\title{
Anti-tumor activity of the proteasome inhibitor bortezomib in gastric cancer
}

\author{
WACHIKO NAKATA ${ }^{1}$, YOKU HAYAKAWA ${ }^{1}$, HAYATO NAKAGAWA ${ }^{1}$, KEI SAKAMOTO ${ }^{2}$, HIROTO KINOSHITA ${ }^{1}$, \\ RYOTA TAKAHASHI ${ }^{1}$, YOSHIHIRO HIRATA ${ }^{1}$, SHIN MAEDA ${ }^{1,3}$ and KAZUHIKO KOIKE ${ }^{1}$ \\ ${ }^{1}$ Department of Gastroenterology, Graduate School of Medicine, The University of Tokyo, 7-3-1 Hongo, \\ Bunkyo-ku, Tokyo 113-8655; ${ }^{2}$ Division of Gastroenterology, Institute for Adult Diseases, Asahi Life \\ Foundation, 1-6-1 Marunouchi, Chiyoda-ku, Tokyo 100-0005; ${ }^{3}$ Department of Gastroenterology, Yokohama \\ City University Graduate School of Medicine, 3-9 Fukuura, Kanazawa-ku, Yokohama 236-0004, Japan
}

Received June 8, 2011; Accepted July 7, 2011

DOI: $10.3892 /$ ijo.2011.1141

\begin{abstract}
The prognosis of unresectable advanced gastric cancer has improved over the last decade due to advances in chemotherapy. However, molecular targeting in gastric cancer therapy has been poorly established and the 5-year survival rate is still $<10 \%$. The proteasome plays a pivotal role in the regulation of cell proliferation, apoptosis and differentiation in a variety of tumor cells. Bortezomib, a selective inhibitor of the proteasome, has prominent effects against several tumor types, including multiple myeloma. We examined the anti-tumor effects of bortezomib on gastric cancer cells in vitro and in subcutaneously transplanted nude mice. We demonstrated that among seven types of gastric cancer cells examined, treatment with bortezomib induced both apoptotic and anti-proliferative effects, resulting in a reduction in cell survival rates. The induction of apoptosis was observed to be dependent on the inhibition of nuclear factor $\kappa \mathrm{B}(\mathrm{NF}-\kappa \mathrm{B})$ activation and the subsequent production of reactive oxygen species (ROS) and c-Jun N-terminal kinase (JNK) activation. Interestingly, we observed that those cells with high levels of NF- $\kappa \mathrm{B}$ activity were resistant to bortezomib treatment. Additionally, we demonstrated that the activation of the extracellular signal-regulated kinase (ERK1/2) was inhibited following bortezomib treatment, which may contribute to its anti-proliferative effects. We also observed anti-tumor effects of bortezomib in vivo. Bortezomib is a potential novel molecular targeting drug for the treatment of unresectable advanced gastric cancer.
\end{abstract}

Correspondence to: Dr Shin Maeda, Department of Gastroenterology, Yokohama City University Graduate School of Medicine, 3-9 Fukuura, Kanazawa-ku, Yokohama 236-0004, Japan

E-mail: shinmaeda2-gi@umin.ac.jp

Key words: bortezomib, proteasome inhibitor, stomach neoplasms, $\mathrm{NF}-\kappa \mathrm{B}$, molecular targeting therapy

\section{Introduction}

Gastric cancer is the second leading cause of cancer deaths worldwide, despite its incidence declining in recent decades. The prognosis of unresectable advanced stomach cancer has improved due to advances in chemotherapy; however, the 5 -year survival rate is still $<10 \%$ (1). Despite extensive efforts, molecular targeting therapies for gastric cancer have been poorly established, whereas antibody-based therapies against vascular endothelial cell growth factor (VEGF) or epidermal growth factor receptor (EGFR) have been used for colorectal cancer $(2,3)$. There is a continuing need for the development of novel therapeutic strategies in the treatment of advanced gastric cancer.

Bortezomib, a proteasome inhibitor, is one of the clinically approved molecular targeting drugs for relapsed or refractory multiple myeloma $(4,5)$. Additionally, bortezomib has been shown to display anti-tumor effects in several solid tumors including gastric, prostate and pancreatic cancer (6-9). It has been suggested that this anti-tumor activity is mediated through affecting various signaling cascades, including the $\mathrm{NF}-\kappa \mathrm{B}$, mitogen-activated protein kinases (MAPKs), and cellular apoptotic pathways (6,7,10-13). However, the precise anti-tumor effects of bortezomib in gastric cancer cells are poorly understood. In the present study, we demonstrated the anti-tumor effects and mechanism of action of bortezomib in human gastric cancer cells in vitro and in vivo.

\section{Materials and methods}

Reagents. Bortezomib was obtained from Janssen Pharmaceutical K.K (Tokyo, Japan). Bortezomib was dissolved with normal saline. We stocked the solution at $-20^{\circ} \mathrm{C}$ and used the stock solution when needed. Z-VAD-fmk was purchased from R\&D Systems (Minneapolis, MN). PD98059 was purchased from Calbiochem (Darmstadt, Germany). DCF-DA was purchased from Invitrogen (Carlsbad, CA).

Gastric cancer cell lines. The human gastric cancer cell lines, MKN1, MKN7 and MKN45, were obtained from RIKEN Gene 
Bank (Ibaraki, Japan). AGS and NCI-N87 cells were obtained from American Type Culture Collection (Manassas, VA). SCH was obtained from the JCRB Cell Bank (Osaka, Japan). TMK-1 was provided by DrE. Tahara (Hiroshima University, Hiroshima, Japan). MKN1 was maintained in DMEM containing 10\% FBS. MKN7, MKN45, SCH, TMK-1 and NCI-N87 were maintained in RPMI-1640 medium containing 10\% FBS. AGS was maintained in nutrient mixture F-12 HAM containing 10\% FBS. These cell lines are incubated at $37^{\circ} \mathrm{C}$ with $5 \% \mathrm{CO}_{2}$.

Antibodies. Anti-phospho-Erk1/2, anti-Erk1/2, anti-phosphoMEK, anti-MEK, anti-cleaved caspase 3, anti-total caspase 3, anti-phospho-JNK, anti-JNK, anti-phospho-I $\kappa \mathrm{B} \alpha$ and antiIKK $\beta$ antibodies were purchased from Cell Signaling (Beverly, MA). Anti-I $\kappa \mathrm{B} \alpha$ and anti-JNK1/3 antibodies were purchased from Santa Cruz Biotechnology (Santa Cruz, CA). Anti- $\beta$-actin antibody was purchased from Sigma-Aldrich (St. Louis, MO).

Cell proliferation assay. Cells were seeded at $0.4-1.5 \times 10^{4}$ cells per well in flat-bottomed 48 -well microplates. After $24 \mathrm{~h}$, cells were treated with bortezomib for the indicated time points or were left untreated. Following drug treatment, cell numbers were determined with Cell Counting Kit- $8^{\circledR}$, according to the manufacturer's protocol (Dojin, Kumamoto, Japan). In brief, cell counting reagent was added to the medium of the cultured cells for $1 \mathrm{~h}$ at $37^{\circ} \mathrm{C}$ with $5 \% \mathrm{CO}_{2}$, then the supernatant was transferred to 96 -well plate and the optical density of the well was measured at $450 \mathrm{nM}$ using microplate reader (Bio-Rad laboratories Inc., Hercules, CA). Cell survival was calculated according to the following formula: cell survival $(\%)=($ optical density (OD) values of experimental groups/OD values of untreated controls) x 100. All experiments were performed in triplicate at least twice and representative results are shown.

Western blotting. Total protein was extracted from culture cells using lysis buffer contains Tris- $\mathrm{HCl}(50 \mathrm{mM}, \mathrm{pH} 7.4)$, Triton $\mathrm{X}-100$ (1\%), EDTA (5 mM), $\mathrm{Na}_{3} \mathrm{VO}_{4}(1 \mathrm{mM}), \mathrm{NaF}(1.25 \mathrm{mM})$, and protease inhibitor cocktail tablets (complete Mini ${ }^{\circledR}$; F. Hoffmann-La Roche, Ltd., Basel, Switzerland; 1T/10 ml) after brief wash with PBS. The lysate was centrifuge for $5 \mathrm{~min}$ at $15000 \mathrm{rpm}$ and supernatant was collected as total protein. Protein concentration was measured using Bio-Rad Protein Assay ${ }^{\circledR}$, according to the manufacturer's protocol (Bio-Rad Laboratories Inc.) and equal amount of proteins was used for Western blotting. The protein was denatured in $4 \mathrm{X}$ sodium dodecyl sulfate (SDS) sampling buffer [Tr-HCl $(250 \mathrm{mM}$, pH 6.8), SDS (8\%), $\beta$-mercaptoethanol (20\%), glycerol (40\%) and bromophenol blue $(0.004 \%)$ ] for $5 \mathrm{~min}$ at $95^{\circ} \mathrm{C}$. Then, the denatured protein was electrophoresed on a $12.5 \%$ SDS-PAGE gel and blotted onto 0.2- $\mu \mathrm{m}$ PVDF membranes (Pall Life Sciences, Port Washington, NY). The membranes were blocked with 5\% (w/v) skimmed milk in TBS-T (Tris-buffered saline containing $0.1 \%$ Tween-20) for $1 \mathrm{~h}$ at room temperature and incubated overnight at $4^{\circ} \mathrm{C}$ with indicated antibodies.

After incubation with the respective primary antibodies, the membranes were washed 3 times for 5 min in TBS-T and then the membranes were incubated with species-specific horseradish peroxidase-linked secondary antibodies (GE Healthcare UK Ltd., Amersham Place, UK) at room temperature for $2 \mathrm{~h}$. Then, after incubation with the secondary antibodies, the membranes were washed 3 times for $5 \mathrm{~min}$ in TBS-T and were detected with ECL plus ${ }^{\circledR}$ (Amersham International plc.) reagent. The expression of $\beta$-actin was used as an internal control. Images were obtained by LAS3000mini ${ }^{\circledR}$ (FujiFilm Corporation, Tokyo, Japan).

Transfection. FLAG-tagged-IKK $\beta$ was subcloned in pRK5, a gift from Dr D. Goeddel (Tularik, San Francisco, CA). RNA oligonucleotides for small interfering RNA (siRNA) were synthesized by Dharmacon Inc. (Lafayette, CO). To achieve transient overexpression of IKK $\beta$, AGS cells were seeded at $1.5 \times 10^{6}$ cells per dish $(10 \mathrm{~cm}$ diameter $)$ and after $24 \mathrm{~h}$, transfected with expression vectors encoding Flag-tagged IKK $\beta$ using Effectene ${ }^{\circledR}$ transfection reagent (Qiagen, Hilden, Germany). At $36 \mathrm{~h}$ following transfection, the cells were seeded at $1.8 \times 10^{4}$ cells per well in flat-bottomed 48 -well microplates. Approximately $70 \%$ of cells expressed IKK $\beta$ by immunofluorescence using anti-flag antibody. Cells were then treated with bortezomib for 24 or 48 h or left untreated. For RNA interference experiments, AGS cells were seeded at $4 \times 10^{3}$ cells per well in flat-bottomed 48 -well microplates in the absence of antibiotics for $24 \mathrm{~h}$ and grown to $30-50 \%$ confluence. The siRNA oligonucleotides $(20 \mathrm{nM})$ were transfected into cells using Lipofectamine ${ }^{\circledR}$ RNAiMAX reagent (Invitrogen) according to the manufacturer's instructions. At $48 \mathrm{~h}$ after siRNA silencing, the cells were treated with bortezomib for 24 or $48 \mathrm{~h}$ or left untreated.

TUNEL assay. Apoptosis was analyzed using an Apoalert DNA Fragmentation Assay kit (Takara Bio, Shiga, Japan).

Detection of ROS. Cells were seeded in 4-chamber glass slides and cultivated with or without bortezomib. Following $6 \mathrm{~h}$ of treatment, cells were incubated with DCF-DA $(10 \mu \mathrm{M})$ for $10 \mathrm{~min}$ and observed by fluorescence microscopy.

Animals. Six-week-old male BALB/cAJcl-nu/nu mice (nude mice) were purchased from CLEA Japan, Inc. (Tokyo, Japan). Animals were maintained under standard laboratory conditions at room temperature with a relative humidity of $55 \pm 5 \%$ (mean \pm standard deviation) and a 12/12-h light/dark cycle. This study was approved by the Ethics Committee for the Institute for Adult Diseases, Asahi Life Foundation. Animal experiments were conducted in accordance with the Guidelines for the Care and Use of Laboratory Animals of Institute for Adult Diseases, Asahi Life Foundation or the University of Tokyo according to the National Institute of Health guidelines.

In vivo evaluation in human tumor xenograft model. Fifteen mice (7 mice: MKN 45, 8 mice: NCI-N87) were inoculated subcutaneously into four points of the back with $5 \times 10^{6} \mathrm{MKN} 45$ cells or NCI-N87 cells per point in $100 \mu \mathrm{l}$ of PBS, respectively. The following week, when the animals had developed tumor nodules of approximately $5 \mathrm{~mm}$ in diameter, mice were randomly assigned into two groups to receive bortezomib or PBS. Treatment with bortezomib $(1 \mathrm{mg} / \mathrm{kg})$ was given intraperitoneally twice per week as previously described in mouse models $(9,14)$. The control group received PBS alone at the same schedule. We measured each greatest diameter of the subcutaneous tumor twice a week and each tumor volume was 
calculated according to the following formula: volume $=4 \pi r^{3} / 3$ ), where $\pi=$ circular constant and $r=$ half of greatest diameter. For short-term analysis following bortezomib treatment, four mice were inoculated subcutaneously into two points of the back with $5 \times 10^{6}$ MKN45 cells per point in $100 \mu \mathrm{l}$ of PBS and two points of the back with $5 \times 10^{6}$ NCI-N87 cells per point in $100 \mu \mathrm{l}$ of PBS. The following week, when the animals had developed approximately $5 \mathrm{~mm}$ tumor nodules, mice were randomly assigned into two groups to receive bortezomib or PBS. Subcutaneous tumors were harvested from xenografts treated with or without bortezomib (1 mg/kg) intraperitoneally for $24 \mathrm{~h}$.

Statistical analyses. Differences in cell survival among cells were assessed using one-way ANOVA with Tukeys and Bonferroni's post-hoc test and data are expressed as means \pm SD. Comparison of subcutaneous tumor growth of xenograft models were done using Mann-Whitney's U test or Welch's t-test and data are reported as means \pm SE. The number of apoptotic cells derived from subcutaneous tumor was analyzed using Mann-Whitney's U test and data are reported as means \pm SD. P-values $<0.05$ were considered statistically significant.

\section{Results}

Growth inhibition of gastric cancer cell lines following bortezomib treatment. We first examined the effects of different concentration of bortezomib using five gastric cancer cell lines (MKN1, MKN7, MKN45, AGS and NCI-N87) in vitro. Cells were treated with different doses of bortezomib for $24 \mathrm{~h}$ and the cell survival rates were analyzed. Fig. 1A demonstrates that the growth of most cell lines was inhibited in a dose-dependent manner at concentrations of 5-100 nM bortezomib. We also found AGS cells and NCI-N87 cells were sensitive to low concentration of bortezomib ( 5 or $25 \mathrm{nM}$ ), but other three cell lines were relatively resistant at low concentration. Thus we examined the time course of the effect of bortezomib at low concentration $(10 \mathrm{nM})$ and high concentration $(100 \mathrm{nM})$ in seven gastric cancer cell lines. As shown in Fig. 1B, at $10 \mathrm{nM}$, cell growth was effectively inhibited in AGS and NCI-N87 in a time-dependent manner, but not in the other five cell lines ( $\mathrm{p}=0.05)$ after $48 \mathrm{~h}$. At $100 \mathrm{nM}$, bortezomib effectively inhibited cell growth in all seven cell lines after $48 \mathrm{~h}$. These results suggest that the cytotoxic sensitivity differs between cancer cells at lower concentrations of bortezomib.

Evaluation of apoptosis induction following bortezomib treatment. Growth inhibition is caused by both decreased cellular proliferation and increased cell death. It has been reported that an induction of apoptosis accounts for the anti-tumorigenic mechanism of bortezomib. As expected, immunoblot analysis demonstrated elevated levels of cleaved caspase 3 , indicative of apoptosis, following bortezomib administration in MKN45 and NCI-N87 cells (Fig. 2A and B). Moreover, Z-VAD-fmk, a pan-caspase inhibitor, blocked the caspase 3 induction mediated by bortezomib, suggesting that bortezomib induced apoptosis in gastric cancer cell lines (Fig. 2C and D).

Effects of $N F-\kappa B$ activity on sensitivity to bortezomib. The inhibition of $\mathrm{NF}-\kappa \mathrm{B}$ activation is the major reported mechanism for bortezomib-mediated apoptosis (7). To confirm this,
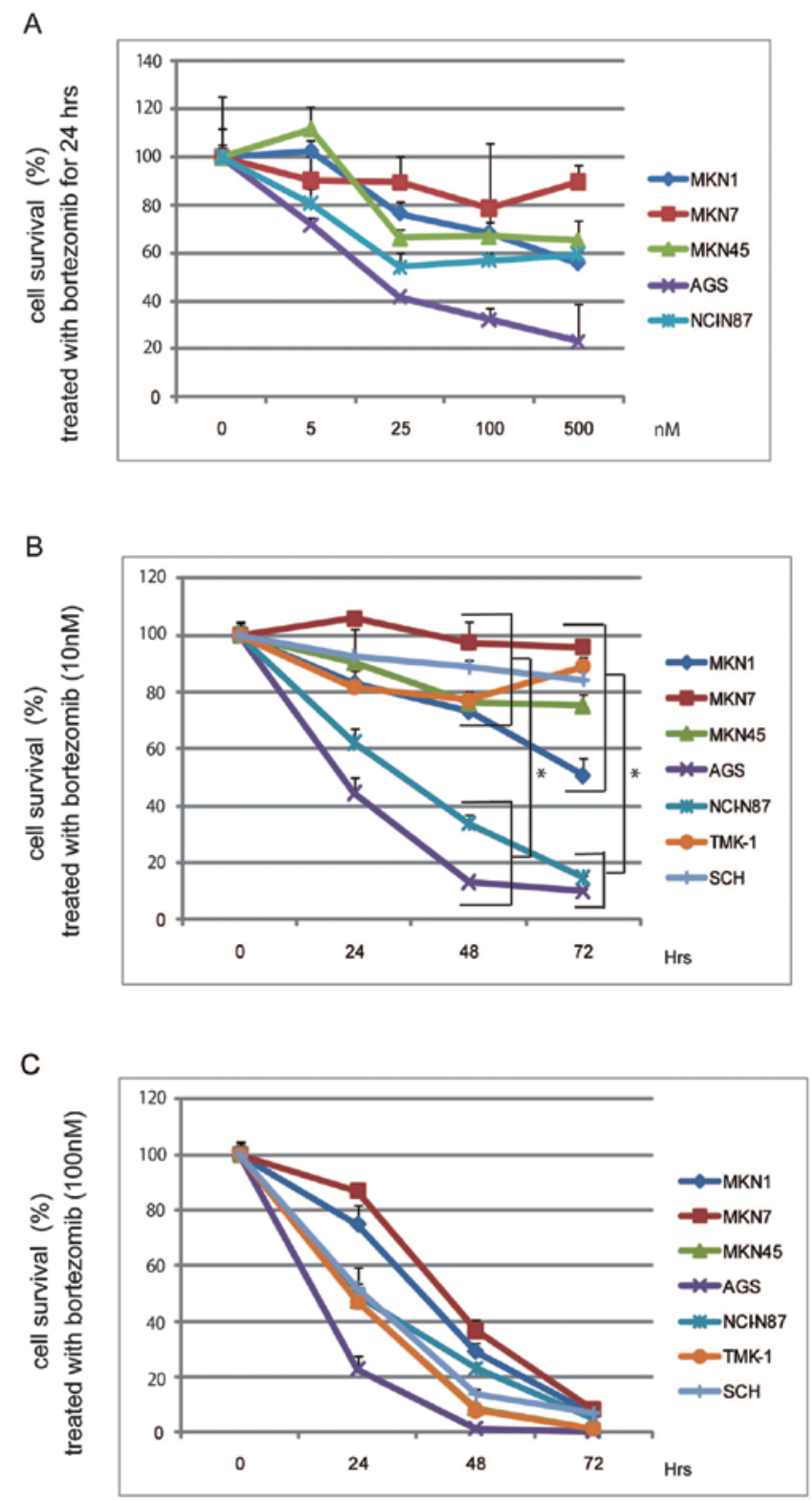

Figure 1. Effects of bortezomib on proliferation of gastric cancer cell lines in vitro. (A) Five human gastric cancer cell lines (MKN1, MKN7, MKN45, AGS and NCI-N87) were treated with different doses of bortezomib. After $24 \mathrm{~h}$ incubation, cell growth was measured using a Cell Counting Kit-8. Cell survival was converted percent to the ratio of $\mathrm{OD}$ values of experimental groups to OD values of untreated controls to percent as described in Materials and methods. (B and C) Seven gastric cancer cell lines (MKN1, MKN7, MKN45, AGS, NCI-N87, SCH and TMK-1) were treated with bortezomib at concentrations of $10 \mathrm{nM}$ (B) or $100 \mathrm{nM}$ (C) for $72 \mathrm{~h}$. At the indicated time points, cell survival was calculated as above.

we assessed basal NF- $\kappa$ B activity by immunoblot analysis of phospho-I $\mathrm{B} \alpha$ in the seven gastric cancercell lines. We observed that MKN1, MKN7, MKN45, SCH and TMK-1 cells displayed a marked activation of phospho-I $\mathrm{KB} \alpha$, while the NCI-N87 and AGS cell lines displayed levels typical of basal NF- $\kappa$ B activity (Fig. 3A). Interestingly, both NCI-N87 and AGS cells, which displayed low levels of NF- $\kappa$ B activity, displayed higher sensitivity to bortezomib treatment (Fig. 1B). We thus assume that basal NF- $\kappa$ B activity may affect the sensitivity of cancer cells to bortezomib. To investigate whether high NF- $\kappa \mathrm{B}$ activity indicates resistance to bortezomib, we overexpressed the I $\mathrm{B}$ 


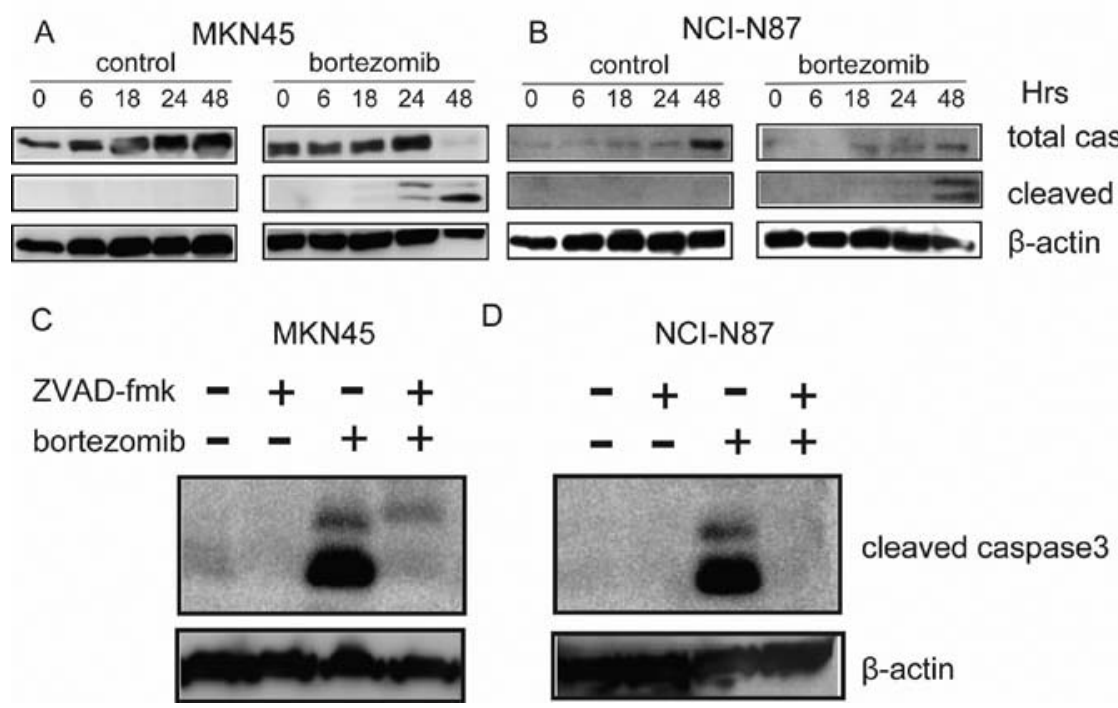

Figure 2. Effects of bortezomib on apoptosis in gastric cancer cells in vitro. MKN45 (A) or NCI-N87 (B) cells were treated with bortezomib (100 or $10 \mathrm{nM}$, respectively). At the indicated time points, cells were lysed, gel-separated and immunoblotted with antibodies against the indicated proteins. MKN45 (C) or NCI-N87 (D) cells were treated with bortezomib $(100 \mathrm{nM})$ for $24 \mathrm{~h}$ in the presence or absence of Z-VAD-fmk $(10 \mu \mathrm{M})$. Cell lysates were immunoblotted with antibodies against the indicated proteins.

A
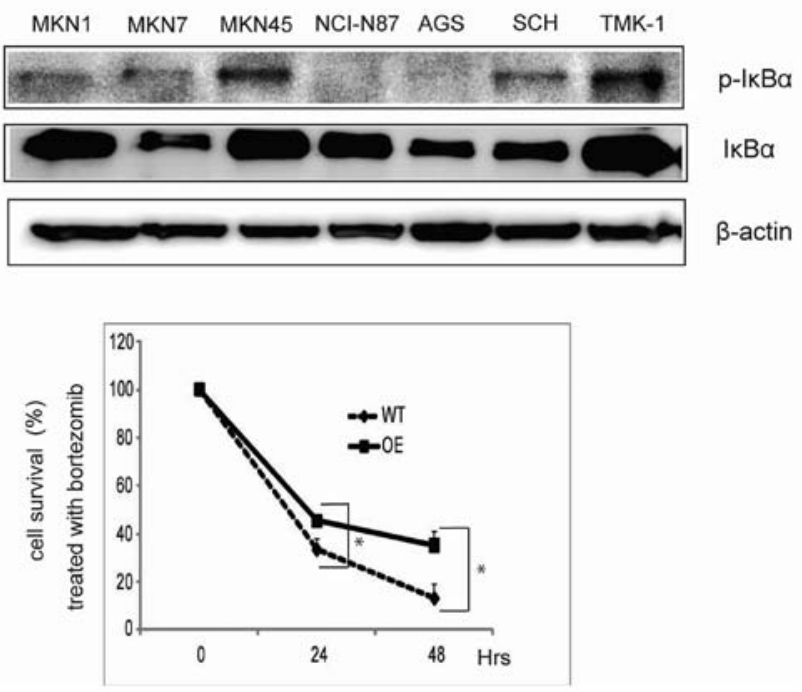

Figure 3. Effects of NF-kB activity on sensitivity to bortezomib. (A) Detection of NF- $\mathrm{kB}$ activity at steady state. After $24 \mathrm{~h}$ incubation, cells were lysed, gelseparated and immunoblotted with antibodies to the indicated proteins. (B) AGS cells transfected with (OE) or without (WT) IKK $\beta$ were treated with bortezomib $(10 \mathrm{nM})$. The cell growth and survival were measured as in Fig. 1.

kinase $\beta$ (IKK $\beta$ ), a key kinase for NF- $\mathrm{kB}$ activation, in AGS cells. Fig. 3B demonstrates that bortezomib-induced growth inhibition in AGS cells was inhibited by IKK $\beta$ overexpression. These results suggest that the basal activation of NF- $\kappa B$ may be a useful biomarker for the effectiveness of bortezomib in gastric cancer cell death.

Bortezomib treatment increases ROS production and JNK activity in gastric cancer cells. An increased level of ROS production following NF- $\mathrm{kB}$ inhibition has been suggested as an important mechanism for increasing cancer cell apoptosis
$(15,16)$. We thus analyzed levels of ROS production following bortezomib treatment, through DCF-DA staining. Fig. 4 demonstrates that treatment with bortezomib strongly induced ROS production, consistent with inhibition of NF- $\mathrm{KB}$ activity. It has previously been reported that JNK activity, mediated by ROS production in NF-kB-inhibited cells, plays a role in the apoptotic cell death process $(15,16)$. As expected, we observed that JNK activity was increased following bortezomib treatment in gastric cancer cells (Fig. 4C and D). Additionally, we observed that, when AGS cells were transfected with small interfering RNA (siRNA) to knockdown levels of JNK1, decreased levels of cellular apoptosis, determined by the expression level of cleaved caspase 3, were observed (Fig. 4E). These results suggest that bortezomib increases both ROS production and JNK activation that eventually lead to the induction of apoptosis and subsequent gastric cancer cell death.

Effects of bortezomib on proliferative signaling pathways in gastric cancer cell lines. It has previously been reported that the activation of MAP kinases, particularly ERK1/2, regulates cellular proliferation. Additionally, it has been reported that bortezomib induces down-regulation of the Raf/MEK/ERK pathway $(13,17)$. We observed that, in NCI-N87 cells, ERK1/2 activation (as assessed by ERK1/2 phosphorylation), was significantly inhibited following bortezomib treatment, while no change in the level of total ERK was evident. Interestingly, activation of the upstream kinase MEK and levels of total MEK were unchanged, suggesting that bortezomib inhibited ERK1/2 independently of MEK inactivation (Fig. 5A). To determine whether inhibition of ERK1/2 activation mediated cellular proliferation, the cell numbers of NCI-N87 cells were assessed following treatment with the specific ERK1/2 inhibitor, PD98059. As expected, PD98059 inhibited cellular proliferation (Fig. 5B, and other data not shown) indicating that bortezomib exerted an inhibitory effect on cellular proliferation through suppression of ERK1/2 signaling. 
A

MKN45

ROS
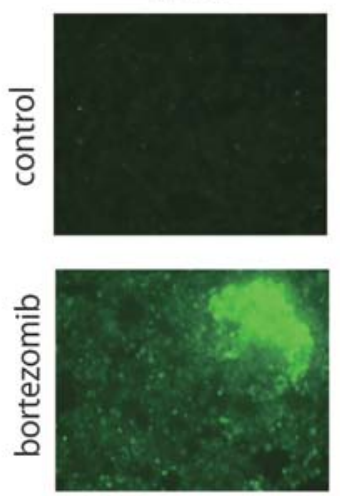

B

NCI-N87

DAPI
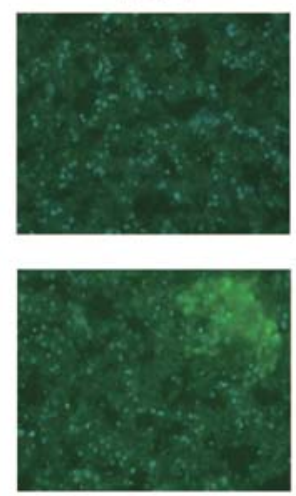

ROS
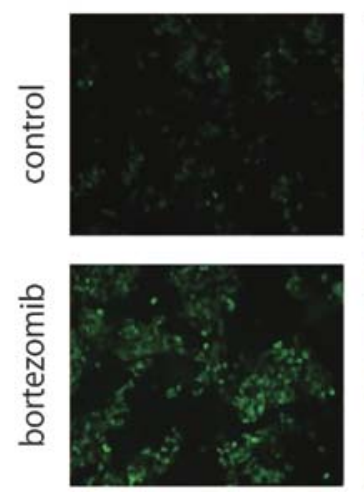

DAPI
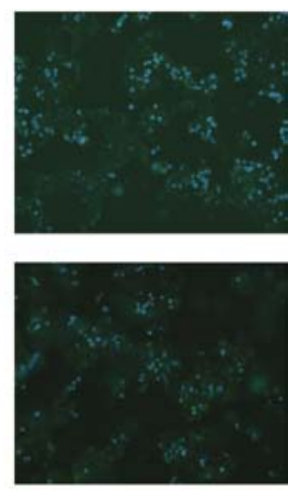

C

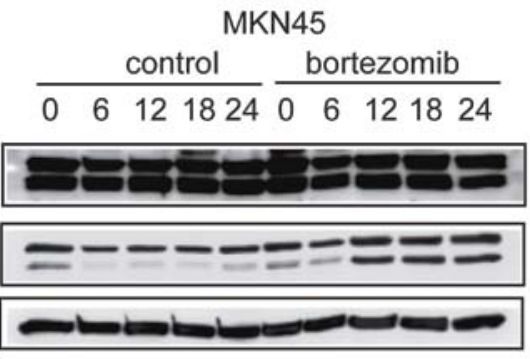

D

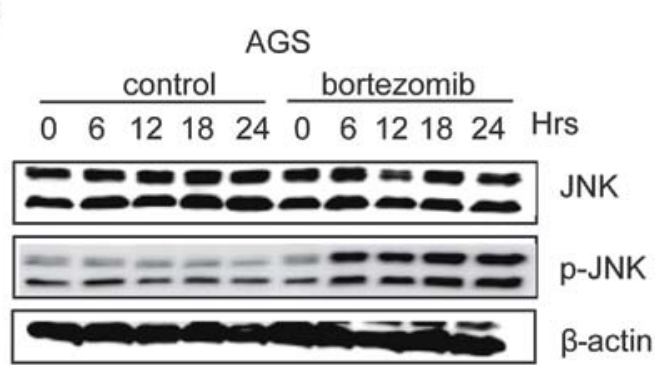

E

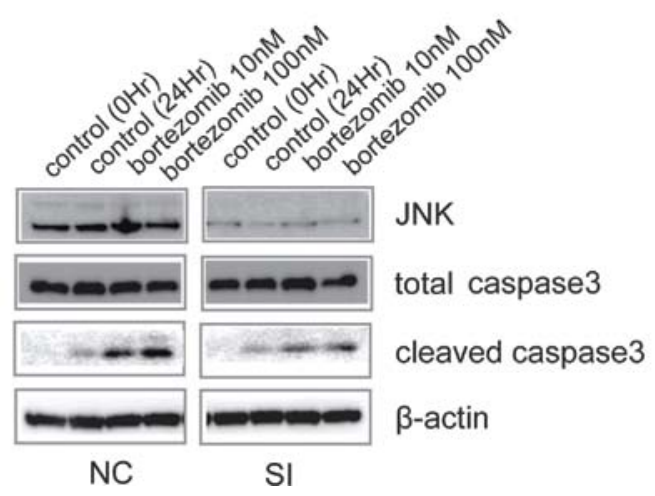

Figure 4. Increased ROS production and JNK activity following bortezomib treatment. MKN45 (A) or NCI-N87 (B) cells were treated with bortezomib (100 nM) for $6 \mathrm{~h}$. Cells were treated with DCF-DA (green) and DAPI (blue) (magnification, x100). MKN45 (C) and AGS (D) cells were treated with bortezomib (MKN45, $100 \mathrm{nM}$; AGS, $10 \mathrm{nM}$ ). At the indicated times, cells were lysed, gel-separated and immunoblotted with antibodies against the indicated proteins. (E) AGS knockdown (SI) or control (NC) cells were treated with bortezomib (10 or $100 \mathrm{nM})$ and at the indicated time points, cells were lysed and immunoblotted with antibodies against the indicated proteins.
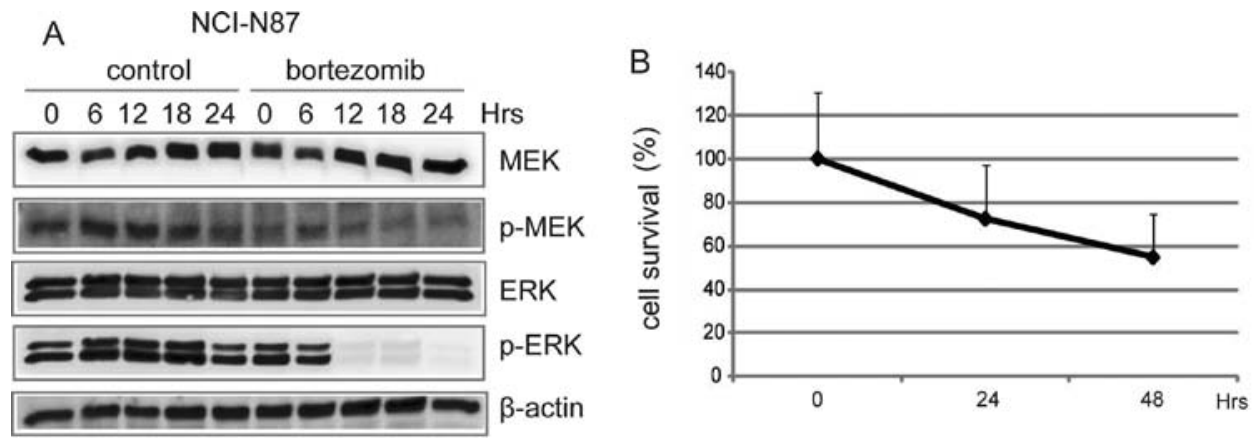

Figure 5. Effects of bortezomib on MAPK signaling. (A) NCI-N87 cells were treated with bortezomib $(10 \mathrm{nM})$. At the indicated time points, cell lysates were immunoblotted with antibodies against the indicated proteins. (B) NCI-N87 cells were treated with or without PD98059 (30 $\mu \mathrm{M})$, and cell growth and survival were evaluated as in Fig. 1. 
A

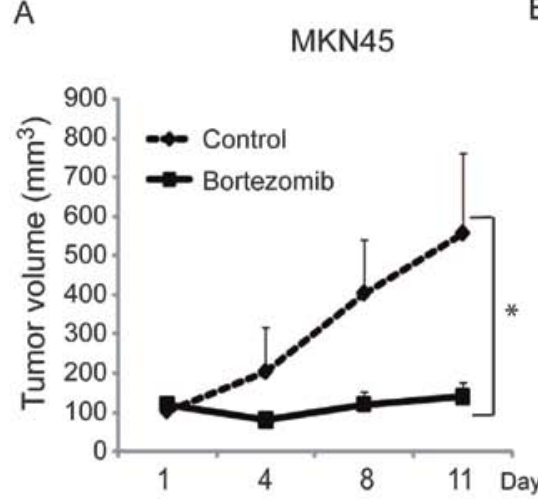

C
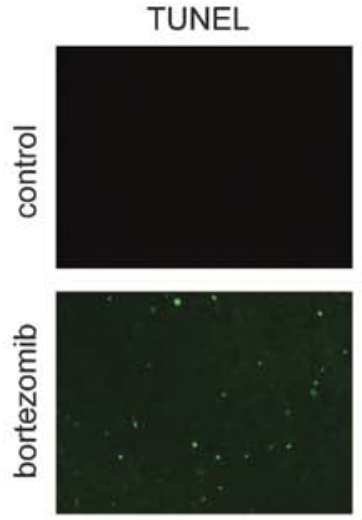

E
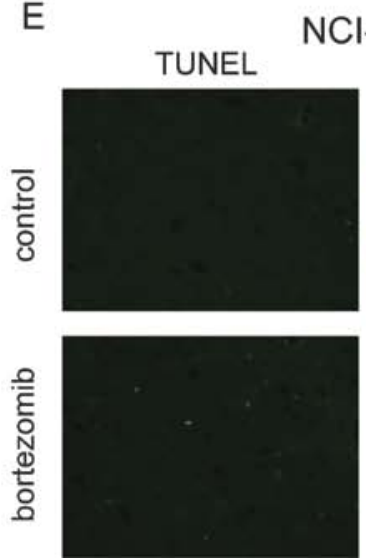

B

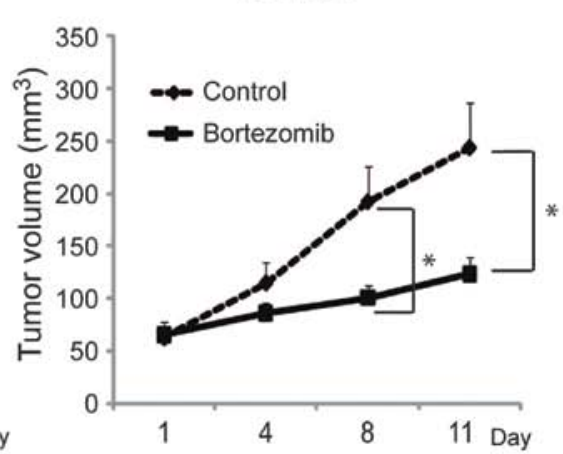

MKN45

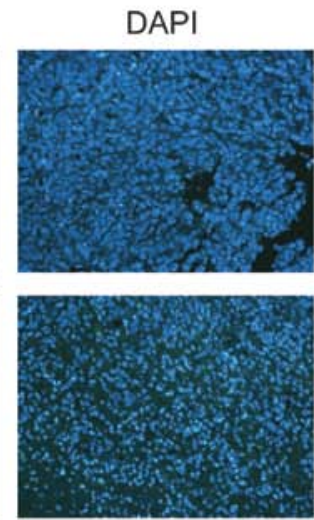

$\mathrm{NCl}-\mathrm{N} 87$

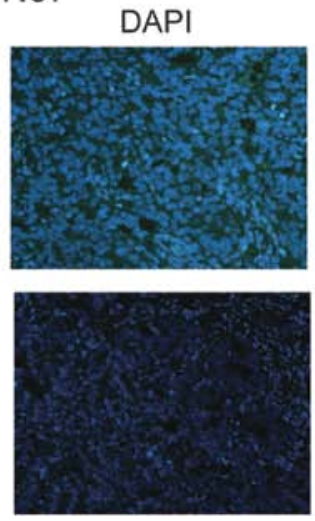

D

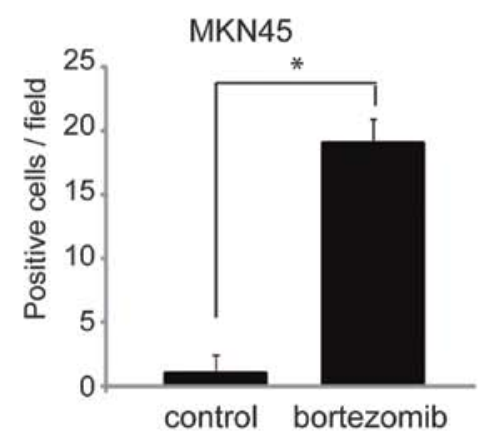

$\mathrm{F}$

$\mathrm{NCl}-\mathrm{N} 87$

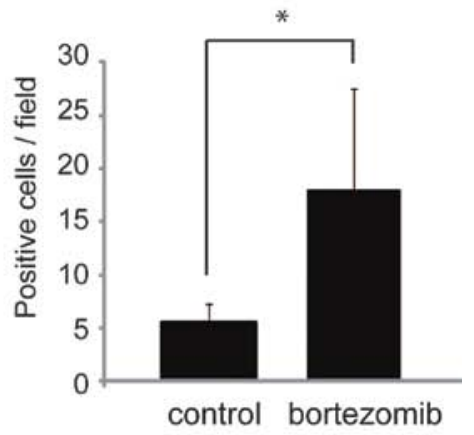

Figure 6. Inhibition of tumor growth following bortezomib treatment in vivo. Subcutaneous tumors of MKN45 (A) or NCI-N87 (B) cells were generated by injecting $5 \times 10^{6}$ cells into nude mice. Tumors developed to $5 \mathrm{~mm}$ in diameter prior to the initiation of therapy. Bortezomib (1 mg/kg) was administered intraperitoneally twice a week. The control group received PBS alone at the same schedule. The greatest diameter of the tumors was measured twice a week and volumes were calculated as described in Materials and methods. TUNEL staining was performed in subcutaneous tumors of MKN45 (C) or NCI-N87 (E) harvested from xenografts treated with or without bortezomib $(1 \mathrm{mg} / \mathrm{kg}$ ) for $24 \mathrm{~h}$ (magnification, x200). The percentage of TUNEL-positive nuclei in each field was calculated; (D) MKN45; (F) NCI-N87.

Bortezomib inhibits tumor growth in established human gastric cancer xenografts. To evaluate the effects of bortezomib on gastric cancer in vivo, xenograft models were established subcutaneously from MKN45 and NCI-N87 cells in nude mice. In this model, when tumors had developed to around $5 \mathrm{~mm}$ in diameter, bortezomib was administered intraperitoneally twice a week. Fig. 6 demonstrates that bortezomib treatment strongly suppressed subcutaneous tumor growth in vivo. Consistent with the in vitro results, TUNEL staining in the extracted tissue demonstrated that the number of apoptotic cells was increased following bortezomib treatment (Fig. 6C-F).

\section{Discussion}

Bortezomib has been effectively used in the treatment of multiple myeloma for over a decade $(4,5)$. Additionally, it has been assessed for use in the therapy of other solid tumors including ovarian (18), pancreatic (8) and prostate cancer (9). Regarding gastric cancer, anti-tumor effects of bortezomib in vitro have been previously reported $(6,7)$. In the current study, we found that bortezomib inhibited cell growth of seven gastric cancer cell lines at a concentration of $100 \mathrm{nM}$ in vitro, and that bortezomib induced apoptosis of these cells. In addition, we analyzed 
the potential mechanism of bortezomib-mediated gastric cell apoptosis, and found basal NF- $\mathrm{BB}$ activity was associated with the sensitivity to bortezomib, suggesting the growth inhibition effect by bortezomib is partly mediated by apoptosis through inhibition of NF- $\kappa \mathrm{B}$. We also demonstrated that bortezomib treatment increased both ROS generation and JNK activation in gastric cancer cells through NF- $\mathrm{NB}$ inhibition. A similar functional mechanism of bortezomib has previously been reported in leukemia cells (12). Taken together, these results suggest that bortezomib inhibits cell growth of gastric cancer cell lines by multiple mechanisms.

Interestingly, we found that the activation levels of $\mathrm{NF}-\kappa \mathrm{B}$ at steady state were variable among the seven cancer cell lines. Those cell lines that displayed low levels of NF- $\kappa \mathrm{B}$ activation, displayed a high responsiveness to bortezomib treatment. To clarify that the basal NF- $\kappa \mathrm{B}$ activity affected the sensitivity to bortezomib treatment, IKK $\beta$ (which induces NF- $\kappa \mathrm{B}$ activation) was overexpressed in AGS cells. Those AGS cells were more resistant to bortezomib treatment, indicating that the activation of $N F-\kappa B$ at steady state could be a predictive biomarker of the therapeutic efficiency of bortezomib.

In this study, IKK $\beta$ was overexpressed transiently in AGS cells, so bortezomib resistance induced by transfection could range in effectiveness according to some experimental conditions. Moreover, bortezomib is expected to be involved in many signal transduction through inhibition of proteasome, it might be taken into consideration that the difference in bortezomib sensitivity among the cell lines was affected by not only the activation levels of $\mathrm{NF}-\kappa \mathrm{B}$ at steady state but also some other unrevealed circumstances.

However, such biomarkers are important in evaluating the sensitivity of gastric cancer cells to bortezomib treatment. The need for biomarkers to assess drug sensitivity is demonstrated by recent clinical trial designed to determine the response rates of first line bortezomib in combination with paclitaxel and carboplatin in patients with metastatic adenocarcinoma of the esophagus, gastroesophageal junction, or gastric cardia (19). The study was discontinued because the tumor response rate was lower than predictive value in the absence of clinical biomarkers.

Our in vivo results demonstrated that not only NCI-N87 cells with low level of basal NF- $\mathrm{BB}$ activity but also MKN45 cells with high level of basal NF- $\mathrm{B}$ activity were sensitive to bortezomib treatment in our experimental conditions. We speculate that the concentration of bortezomib in subcutaneous tumors reached a higher level than concentration in vitro, which might sensitize both cell lines to bortezomib.

One clinical trial designed to examine the effectiveness of bortezomib on metastatic gastric adenocarcinoma reported that bortezomib was inactive as a single agent (20). The discrepancy of sensitivities between experimental models in vitro or in vivo and clinical trials may be caused by concentration of bortezomib in tumors as well as microenvironment surrounding tumors, such as $\mathrm{pH}$, vascularization and $\mathrm{O}_{2}$ concentration. Unfortunately our xenograft model has limitations for assessing these tumor environments. Thus, future studies will be required to elucidate the conditions in which bortezomib display maximal anti-tumor activity.

In this study, we demonstrate that bortezomib monotherapy displays a marked effectiveness in a gastric cancer xenograft model. In general, molecular targeting drugs have been used in combination with standard chemotherapy. It will be useful to analyze the effects of bortezomib in combination with other chemo-drugs, particularly docetaxel, 5-FU or cisplatin, which display markedly increased tumor cell growth suppression in gastric cancer cell lines in vitro (7). As the mouse model used in this study did not develop metastatic tumors, the effect of bortezomib on metastatic gastric tumors is not clear. Thus, it will be helpful to use other mouse models which actually develop metastasis (21) to confirm the effect bortezomib with other chemotherapy drugs on advanced gastric tumors.

In summary, we found that bortezomib suppresses gastric cancer cell proliferation in vitro and in vivo and that bortezomib is more effective in gastric cancer with lower NF- $\mathrm{B}$ activation. These results suggest that bortezomib could be an option as a therapy of gastric cancer especially with low levels of $N F-\kappa B$ activation.

\section{Acknowledgements}

S.M. was supported by grants-in-aid from the Ministry of Education, Culture, Sports, Science and Technology of Japan (22300317).

\section{References}

1. Maruyama K, Kaminishi M, Hayashi K, Isobe Y, Honda I, Katai H, Arai K, Kodera Y and Nashimoto A: Gastric cancer treated in 1991 in Japan: data analysis of nationwide registry. Gastric Cancer 9: 51-66, 2006.

2. Tabernero J, Van Cutsem E, Diaz-Rubio E, Cervantes A, Humblet Y, Andre T, Van Laethem JL, Soulie P, Casado E, Verslype C, Valera JS, Tortora G, Ciardiello F, Kisker O and de Gramont A: Phase II trial of cetuximab in combination with fluorouracil, leucovorin, and oxaliplatin in the first-line treatment of metastatic colorectal cancer. J Clin Oncol 25: 5225-5232, 2007.

3. Kabbinavar FF, Hambleton J, Mass RD, Hurwitz HI, Bergsland E and Sarkar S: Combined analysis of efficacy: the addition of beva cizumab to fluorouracil/leucovorin improves survival for patients with metastatic colorectal cancer. J Clin Oncol 23: 3706-3712, 2005.

4. Richardson PG, Sonneveld P, Schuster MW, Irwin D, Stadtmauer EA, Facon T, Harousseau JL, Ben-Yehuda D, Lonial S, Goldschmidt H, Reece D, San-Miguel JF, Blade J, Boccadoro M, Cavenagh J, Dalton WS, Boral AL, Esseltine DL, Porter JB, Schenkein D and Anderson KC: Bortezomib or high-dose dexamethasone for relapsed multiple myeloma. $\mathrm{N}$ Engl J Med 352: 2487-2498, 2005.

5. San Miguel JF, Schlag R, Khuageva NK, Dimopoulos MA, Shpilberg O, Kropff M, Spicka I, Petrucci MT, Palumbo A, Samoilova OS, Dmoszynska A, Abdulkadyrov KM, Schots R, Jiang B, Mateos MV, Anderson KC, Esseltine DL, Liu K, Cakana A, van de Velde $\mathrm{H}$ and Richardson PG: Bortezomib plus melphalan and prednisone for initial treatment of multiple myeloma. N Engl J Med 359: 906-917, 2008.

6. Fujita T, Doihara H, Washio K, Ino H, Murakami M, Naito M and Shimizu N: Antitumor effects and drug interactions of the proteasome inhibitor bortezomib (PS341) in gastric cancer cells. Anticancer Drugs 18: 677-686, 2007.

7. Bae SH, Ryoo HM, Kim MK, Lee KH, Sin JI and Hyun MS: Effects of the proteasome inhibitor bortezomib alone and in combination with chemotherapeutic agents in gastric cancer cell lines. Oncol Rep 19: 1027-1032, 2008.

8. Nawrocki ST, Sweeney-Gotsch B, Takamori R and McConkey DJ: The proteasome inhibitor bortezomib enhances the activity of docetaxel in orthotopic human pancreatic tumor xenografts. Mol Cancer Ther 3: 59-70, 2004.

9. Williams S, Pettaway C, Song R, Papandreou C, Logothetis C and McConkey DJ: Differential effects of the proteasome inhibitor bortezomib on apoptosis and angiogenesis in human prostate tumor xenografts. Mol Cancer Ther 2: 835-843, 2003. 
10. Hideshima T, Richardson P, Chauhan D, Palombella VJ, Elliott PJ, Adams J and Anderson KC: The proteasome inhibitor PS-341 inhibits growth, induces apoptosis, and overcomes drug resistance in human multiple myeloma cells. Cancer Res 61: 3071-3076, 2001.

11. LeBlanc R, Catley LP, Hideshima T, Lentzsch S, Mitsiades CS, Mitsiades N, Neuberg D, Goloubeva O, Pien CS, Adams J, Gupta D, Richardson PG, Munshi NC and Anderson KC: Proteasome inhibitor PS-341 inhibits human myeloma cell growth in vivo and prolongs survival in a murine model. Cancer Res 62 4996-5000, 2002

12. Yu C, Rahmani M, Dent P and Grant S: The hierarchical relationship between MAPK signaling and ROS generation in human leukemia cells undergoing apoptosis in response to the proteasome inhibitor Bortezomib. Exp Cell Res 295: 555-566, 2004.

13. Small GW, Shi YY, Edmund NA, Somasundaram S, Moore DT and Orlowski RZ: Evidence that mitogen-activated protein kinase phosphatase-1 induction by proteasome inhibitors plays an antiapoptotic role. Mol Pharmacol 66: 1478-1490, 2004.

14. Chen KF, Yeh PY, Yeh KH, Lu YS, Huang SY and Cheng AL: Down-regulation of phospho-Akt is a major molecular determinant of bortezomib-induced apoptosis in hepatocellular carcinoma cells. Cancer Res 68: 6698-6707, 2008.

15. Kamata H, Honda S, Maeda S, Chang L, Hirata H and Karin M: Reactive oxygen species promote TNFalpha-induced death and sustained JNK activation by inhibiting MAP kinase phosphatases. Cell 120: 649-661, 2005.

16. Sakon S, Xue X, Takekawa M, Sasazuki T, Okazaki T, Kojima Y, Piao JH, Yagita H, Okumura K, Doi T and Nakano H: NF-kappaB inhibits TNF-induced accumulation of ROS that mediate prolonged MAPK activation and necrotic cell death. EMBO J 22: 3898-3909, 2003.
17. Dasmahapatra G, Rahmani M, Dent P and Grant S: The tyrphostin adaphostin interacts synergistically with proteasome inhibitors to induce apoptosis in human leukemia cells through a reactive oxygen species (ROS)-dependent mechanism. Blood 107: 232-240, 2006.

18. Bazzaro M, Lee MK, Zoso A, Stirling WL, Santillan A, Shih IeM and Roden RB: Ubiquitin-proteasome system stress sensitizes ovarian cancer to proteasome inhibitor-induced apoptosis. Cancer Res 66: 3754-3763, 2006.

19. Jatoi A, Dakhil SR, Foster NR, Ma C, Rowland KM Jr, Moore DF Jr, Jaslowski AJ, Thomas SP, Hauge MD, Flynn PJ, Stella PJ and Alberts SR: Bortezomib, paclitaxel, and carboplatin as a first-line regimen for patients with metastatic esophageal, gastric, and gastroesophageal cancer: phase II results from the North Central Cancer Treatment Group (N044B). J Thorac Oncol 3: 516-520, 2008

20. Shah MA, Power DG, Kindler HL, Holen KD, Kemeny MM, Ilson DH, Tang L, Capanu M, Wright JJ and Kelsen DP: A multicenter, phase II study of Bortezomib (PS-341) in patients with unresectable or metastatic gastric and gastroesophageal junction adenocarcinoma. Invest New Drugs (In press).

21. Fujihara T, Sawada T, Hirakawa K, Chung YS, Yashiro M, Inoue $\mathrm{T}$ and Sowa M: Establishment of lymph node metastatic model for human gastric cancer in nude mice and analysis of factors associated with metastasis. Clin Exp Metastasis 16: 389-398, 1998 